4. Dat alle muscaatboomen, die sij weten ofte sullen comen te weten, aldlaar te staan, aan d'Hollanders daar comende, sullen ontdekken, en in hare tegenwoordigheijt omslaan voor den geaccordeerden prijs, op pene van gehouden te werden als ongehoorsame onderdanen en verbontbrekers.

5. Dat daar voor d'E. Comp ${ }^{\circ}$ de bescherminge ende heerschappije aanneemt over haer, tegen alle en een ijcler, die haer eenige schade ofte leet aandoen ofte willen, als sij Serouwers sulx versoeken, belovende de hoog gemelte E. Compr voorder haar met alle vruntschap te bejegenen, als een goet heer sijne onderclanen schuldig is te cloen.

Deze bovenstaande articulen worden wedersijts belooft, sonder Eenige de minste infractie in alles punctuelijck nagecomen en de agtervolgt te sullen werden, doende de orangcaijs ende inwoonders van .... ${ }^{1}$ ) ingevolge bij desen per hare gewoonlijcke formaliteijten, solemnelijck aan de E. Comp ${ }^{c}$ den eedt van getrouwe onderdanigheiji, waarop aen de selve een vlagge, waer in die onderdanigheijt staat liijtgedrukt, neffens een steene voet, waerin hooggemelte E. Comps wapen en merk is uijtgehouwen, wordt behandigt, en bij haar wordt aengenomen, om daardoor sig selven als sodanig aan alle aancomencle volckerèn te vertoonen.

Aldus gedaan en vastgestelt op 't eijlant Serouwa den $6^{\circ}$ Martij A" 1664 en van dese onderstaande Orangcaijs geteekent: dit is 't merck van orangcaij Saijse, orangcang Monij, orangcaij Marasij, orangcaij Ablau, Jacob Sas, Jan van der Linde, Isbrant Petrus Ermunt, Martijn Claeszoon Trouw en Michiel Hendrix.

\title{
CCLXXXIV. BANDA.
}

\section{Maart 1664. " )}

De fluit Loenen deed volgens haar „ordre” Damar aan om ook dacr het gezag onzer O. I. C. te bevestigen. (Vgl. Corp. Dipl. I, bldz. 475, v.r.: 1)agh-Rcyister 1664, bldz. 231 v.v.). De Engelschen beweerden spoedigs daarna „dit eiland in possessie genomen" te hebben, een bericht, dat juist bleek te zijn, ook voorzoover Nila betreft. „De meeste part der inhabitanten van 't eijlant Damme hebben haer vrijwillig gestelt onder de pro-: tectie van zijn Maijt Charles de Secunde", schreven de Fngelsche vain

1) ?

$\Rightarrow$ Uit het Contractboek. 
Damar uit den 18 April 1664. Van Dam maakte korte metten en bracht de bewoners van beide eilanden nog in 1664 onder de gehoorzaamheid onzer O. I. C. terug. De leiders der Engelsche expeditie werden naar Batavia gezonden en de voornaamste onder hen, een Nederlandschen deserteur Vincent Vette, ,geconfineert in 't dol': uijs, on daer wat beter sinnen te krijgen". Den 3 December 1664 werd order gegeven aan de Bandasche autoriteiten, ,geen vasticheden op Dame, Saroua en Nijlle te leggen, maar op yder 2 Nederlanders en 1 à 2 Mardyckers". ${ }^{1}$ )

In den jare na s'werelts geboren Heijl (den Emanuel Jesus Christus) 1664: op den 30 Martij, hebben wij (afgesondene van den $\mathrm{E}$. Heer Johan van Dam, raat extraordinair van India, Gouverneur en Directeur over d'eijlanden Banda), Jacob Sas, schipper en geconstitueert opperhooft, Jan van der Linde, sergeant en militair hooft, Isbrant Petrus Ermunt, adsistent, Martijn Claeszoon Trouw, stierman ende den provis $^{\mathrm{cn}}$ sergeant Michiel Hendrix, door hoog gemelte sijn $\mathrm{E}^{\mathrm{s}}$ wel gegeven ordres, uijt den name van den Ed $d^{e}$ Heer Joan Maatsuijcker, Gouverneur-Generaal over gants Nederlants Orienten. van wegen de Vereenigde Nederlantse staat in 't Oosten, aan de eene sijde, ende de Orangcaijs des eijlants Damme, voor haer selven, hare successeuren en onderdanen, aen d'ander sijde, te samen een eeuwig duijrend verbont opgerigt in maniere en op conditiën hier na volgende:

Dat de Orangcaijs van Damme, ook uijt den name van hare successeuren ende onderhorige, haar selve stellen tot onderdanen aan de Vereenigde Nederlantse Oost-Indische Comp".

Dat sij haer selven verbinden, geen andere natiën, 't sij blancke of swarte, als alleen d'Hollanders op hare stranden (veel min op haer eijlant) t'admitteren.

Dat veel weijniger hare specerijen aen eenige andere volckeren. dan alleen aen d'hoog gemelte E. Comp' sullen laten toecomen.

Dat alle muscaetboomen, die sij weten, of mogen comen te weten, aldaer te staan, aan de Hollanders daar comende, sullen ontclecken. en in hare tegenwoordigheit voor den geaccordeerclen prijs omslaan, op pene van gehouden te worden, als ongehoorsame onderdanen en verbontbrekers.

1) „Mardijkers zijn vrijluijden off Heijdenen om de Oost”. (Versamcling; vgl. Encyclopacdie N. I. II, bldz. 675 en I, bldz. 422, v., sub voce „Purgers”). 
Dat daervoor d'E. Comp de bescherminge en heerschappije over haer aenneemt tegen alle ende een ijder die haer eenige schacle of leet aandoen willen, als sij Dammesen stix versoeken, belovencle d'hoog gem. E. Comp" haar met alle vruntschap te bejegenen, als een goet heer aan sijne goede onderdanen schuldig is te doen.

Dese bovenstaande conditiën en articulen worden wedersijts belooft, soncler eenige de minste infractie, in alles punctuelijck nagecomenende agtervolgt te sullen worden, doende d'Orangcaijs ende d'inwoonders van Dammen ingevolge hij desen solemnele aan d'E. Comp ${ }^{\mathrm{e}}$ den eedt van getrouwe onderdanigheit, waarop aan de selve tot teeken een vlagg waer in die onderdanigheit staat uijtgedruct. neffens een steene voet, waerin hooggemelte E. Comps wapen encle merk is uijtgehouwen, wort behandigt, ende bij haar aengenomen. om daardoor sig selven als sodanig aan alle aencomende volckeren te vertonen.

Aldus vastgestelt en gedaan op 't eijlant Damme, ten dage alsvoren en was onderteekent 't merck des orangcaijs Kerij van Ilij ${ }^{1}$ ) en Kelijwawe, ${ }^{2}$ ) des orangcaijs Lekij van Kolouette, ${ }^{3}$ ) des orangkaijs Satij van de negorije Beber, ${ }^{4}$ ) cien capiteijn Tewarkaij ter negorije Jeij, 5) des orangcaijs Mennique van de negorye Kommer, ") Jacob Sas, Jan van der Linde, Isbrant Petrus Ermunt, Marten Claeszoon Trouw en Michiel Hendrikx.

\section{BANDA.}

\section{Juli 1664. ${ }^{(i)}$}

„Op Damme ende Nila is weijnig apparentic om swavel te krijgen, want d'Engelsen hebben op Nile ook een logie gestabileert. Daer swerft noch cen Engels schip met 26 stucken omtrent die eijlanden....". Den 5 Juni werd eenige „chaloupen” met „een tropje van 40 soldaten” naer Nila gezonden, om de bewoners ,door die macht en met behulp der Dammanczen
1) Illi.
2) Kelie?
3) Koelwati?
4) Bebber.
5) ?
i) Uit het Contractboek. 